\title{
Factors Delaying End Ejection from End Systole of Ventricle
}

\author{
Hiroyuki Suga, M.D.
}

\section{Summary}

Although the end of ejection of the left ventricle has been generally accepted as almost synonymous with the end of mechanical systole of the ventricle, recent experimental studies showed the cases in which end ejection lagged markedly behind end systole as identified by the time at which the ventricular pressure-volume data point reached the peak isovolumic pressure-volume relation curve. To obtain a better insight into cardiovascular conditions of the delayed end ejection, a computer simulation study was carried out in which the performance of a time-varying elastance model of the ventricle connected with a modified Windkessel model of the arterial load was analyzed. Any change in the Windkessel parameters, ventricular contractility and heart rate sensitively shifted end ejection relative to end systole. Although end ejection coincided with end systole under limited circumstances, end ejection variably lagged behind end systole under most circumstances. These results suggest that the interval between end systole and end ejection of the left ventricle in vivo is also variable depending on changes in the arterial loading conditions, ventricular contractility and heart rate.

\section{Additional Indexing Words:}

Cardiac events Cardiac mechanics Cardiac contraction Relaxation Diastole

7 HE physiological significance of the end-systolic pressure-volume relationship for characterizing the ventricular pumping capability has been gradually recognized in mammalian and human hearts. ${ }^{1-8)}$ In the pressurevolume diagram, the end of mechanical systole of the ventricle as a whole has been defined as the time of the peak isovolumic pressure and the time at which the pressure-volume loop of an ejecting contraction reaches or approaches closest to the peak isovolumic pressure-volume relation curve. On the other hand, in the tracings of ventricular pressure and volume as a function of time, end systole has been recognized as almost synonymous with the end of ejection

From the Department of Cardiac Physiology, National Cardiovascular Center Research Institute, Suita, Osaka 565, Japan.

Received for publication March 6, 1981. 
identified by the dicrotic notch of the ventricular pressure curve or the minimal volume point according to Wigger's diagram of the representative relationships of events in cardiac cycle. ${ }^{91}$

Recent animal experiments evidently showed the cases in which end ejection occurred markedly later than end systole. ${ }^{10 /-12)}$ In these cases, the end-ejection pressure-volume relationship curve was significantly deviated downward from the end-systolic pressure-volume relationship curve. Consequently, if the ventricular pumping capability is evaluated by the end-ejection pressure-volume relationship, it may be variably underestimated depending on the deviation of end ejection from end systole.

With these backgrounds, the cardiovascular conditions influencing the timing of end ejection relative to end systole remain to be elucidated. To obtain an insight into the problem, the hemodynamic coupling between the left ventricle and the arterial loading system was simulated on a digital computer and the cardiovascular parameters shifting end ejection relative to end systole were analyzed.

\section{Methods}

First of all, let me explain what is the definition of the end of mechanical systole of the ventricle. The end systole is the time point in the cardiac cycle at which the mechanical contraction of the ventricle as a whole becomes maximal and the relaxation starts. The end systole of this definition is identical with the pressure-volume point of a pressure-volume loop which reaches or approaches closest to the peak isovolumic pressure-volume curve in the pressure-volume diagram ${ }^{1,2,2)}$ and also with the time at which the timevarying pressure-volume relationship curve of the ventricle rotates steepest or leftmost. ${ }^{31,11,7)}$ For morc details, see Fig. 2 of the previous paper. ${ }^{13}$ )

In the present simulation, the left ventricle was modelled as a timevarying elastance $\mathbf{E}(\mathrm{t})(\mathrm{mmHg} / \mathrm{ml})$ according to the previous findings published in literature ${ }^{3), 4,7,14), 15)} \mathrm{E}(\mathrm{t})$ is the time-varying slope of the instantaneous pressure to volume ratio, i.e. $\mathrm{P}(\mathrm{t}) /[\mathrm{V}(\mathrm{t})-\mathrm{Vd}]$, where $\mathrm{P}(\mathrm{t})(\mathrm{mmHg})$ and $\mathrm{V}(\mathrm{t})(\mathrm{ml})$ are instantaneous ventricular pressure and volume, and $\mathrm{Vd}$ is a small dead volume of $V(t)^{3), 4}$ Thus, when $E(t)$ and $V(t)$ are given, $P(t)$ can be obtained as $E(t)[V(t)-V d]$.

Since the actually obtained $E(t)$ of an ejecting contraction appears a skewed sinusoidal curve largely independent of pre- and afterload, $\mathrm{E}(\mathrm{t})$ was given as equal to $0.5 \mathrm{Emax}[\sin (2 \pi \mathrm{ft}-0.5 \pi)+1]$ during systole and $0.5 \mathrm{Emax}-$ $\left[\sin \left(3 \pi f\left(t-t_{e s}\right)+0.5 \pi\right)+1\right]$ during diastole until $E(t)$ reaches zero, where Emax is end-systolic maximal $\mathrm{E}(\mathrm{t})$. $\mathrm{E}(\mathrm{t})$ remained zero until next contrac- 
tion started. End systole is equal to $t=t_{e s}=0.5 / f(\mathrm{sec})$, where $\mathrm{f}(\mathrm{Hz}$, or beats $/$ $\mathrm{sec}$ ) is heart rate.

The ventricle was assumed to be filled up to end-diastolic volume Ved $(\mathrm{ml})$ by the end of diastole. During systole, given aortic flow $\mathrm{I}(\mathrm{t})(\mathrm{ml} / \mathrm{sec})$, ventricular volume $V(t)=\mathrm{Ved}-\int_{0}^{t} \mathrm{I}(\mathrm{t}) \mathrm{dt}$.

The ventricle was connected to a modified Windkessel afterload model as shown in Fig. 1. This afterload model is a modified Windkessel model or a modified Westerhof et al's model. ${ }^{16)}$ TPR and $(i$ are the total peripheral resistance and the arterial compliance. $R$ and $L$ are the sums of the valvular and aortic resistances and inertances, respectively. The dimensions of TPR, $\mathrm{C}, \mathrm{R}$, and $\mathrm{L}$ are $\mathrm{mmHg} \mathrm{sec} / \mathrm{ml}, \mathrm{ml} / \mathrm{mmHg}, \mathrm{mmHg} \mathrm{sec} / \mathrm{ml}$, and $\mathrm{mmHg} \mathrm{sec} 2 / \mathrm{ml}$. The diode in the diagram represents the aortic valve, allowing forward flow only and stopping any backward flow. The present model seems virtually identical with the hydraulic model used by Ishide et al ${ }^{111}$ in terms of impedance characteristics.

The differential equations describing the present system are:

$$
\begin{aligned}
\mathrm{dI}(\mathrm{t}) / \mathrm{dt} & =[\mathrm{E}(\mathrm{t})[\mathrm{V}(\mathrm{t})-\mathrm{Vd}]-\mathrm{Pa}(\mathrm{t})-\mathrm{RI}(\mathrm{t})] / \mathrm{L} \\
\mathrm{dV}(\mathrm{t}) / \mathrm{dt} & =-\mathrm{I}(\mathrm{t}) \\
\mathrm{dPa}(\mathrm{t}) / \mathrm{dt} & =[\mathrm{I}(\mathrm{t})-\mathrm{Pa}(\mathrm{t}) / \mathrm{TPR}] / \mathrm{C}
\end{aligned}
$$

during ejection. $\mathrm{Pa}(\mathrm{t})$ is aortic pressure $(\mathrm{mmHg})$. Before and after ejection, $I(t)=0$ and

$$
\mathrm{dPa}(\mathrm{t}) / \mathrm{dt}=-\mathrm{Pa}(\mathrm{t}) /(\mathrm{C} \text { TPR })
$$

These ordinary differential equations were solved simultaneously by the Runge-Kutta method on a digital computer (DEC, Minc-11). The integra-

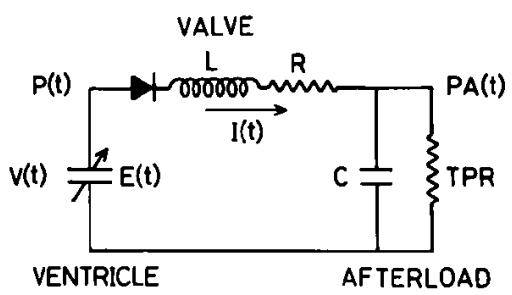

Fig. 1. Simulation of the interaction of the heart ventricle and the afterload system. The left ventricle is represented by the time-varying elastance, $\mathbf{E}(\mathrm{t})$. The afterload system is represented by a modified Windkessel consisting of the vascular compliance (C), total peripheral resistance (TPR), the sum of the characteristic resistance of the aorta and the valvular resistance $(R)$, and the sum of the aortic and valvular inertances $(L), V(t)$ is ventricular volume, $P(t)$ is ventricular pressure, $I(t)$ is aortic flow, and $\mathrm{Pa}(t)$ is aortic pressure. The diode represents the aortic valve stopping reversed flow. 
tion step was 5 msec. Computed $\mathrm{P}(\mathrm{t}), \mathrm{V}(\mathrm{t}), \mathrm{I}(\mathrm{t})$, and $\mathrm{Pa}(\mathrm{t})$ were displayed on a graphic terminal and hard-copied. End ejection was identified as the time when $I(t)$ became zero or negative last time in a contraction cycle. Both end ejection and end systole were printed numerically with a time resolution of $5 \mathrm{msec}$. All the system parameters were scanned over wide ranges and the relations between end ejection and end systole were analyzed.

\section{Results}

Fig. 2 shows a set of isochronal zones of end ejection when inertance $L$ and resistance $\mathrm{R}$ were varied widely while other parameters were kept constant as listed in the figure. Since the resolution in time of end ejection was $5 \mathrm{msec}$, identical to the integration step, the black isochronal zones were drawn for every $10 \mathrm{msec}$ and the white zones between two black zones for the intermediate 5 msec's between the neighboring $10 \mathrm{msec}$ 's. End ejection coincided with end systole $(250 \mathrm{msec}$ for $\mathrm{f}=2 \mathrm{~Hz}$ ) only when $R$ and $L$ were on the hatched isochronal zones for $250 \mathrm{msec}$. For $\mathrm{R}$ and $\mathrm{L}$ in the ranges between the hatched zones and the dashed lines immediately below them, end ejection occurred slightly before end systole. For all other R and L, end ejection did occur variably later than end systole.

The star mark in the middle of Fig. 2 indicates a set of $R$ and $L$ that

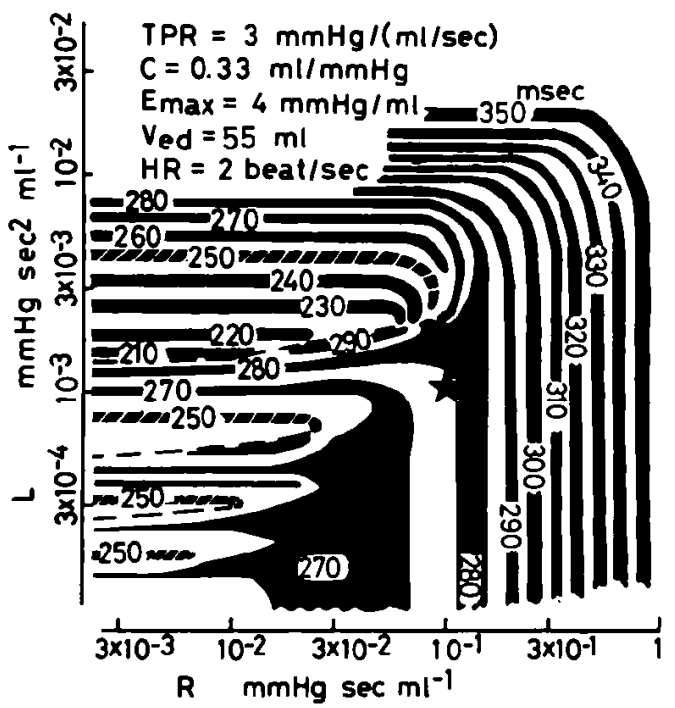

Fig. 2. Isochronal zones of end ejection with both $\mathbf{R}$ and $\mathbf{L}$ changed while the other parameters fixed as specified. End systole is $250 \mathrm{msec}$ at the specified heart rate. The star indicates the combination of $R$ and $L$ that allowed normal contours of ventricular pressure, volume, and flow. $1 \mathrm{mmHg}$ $\mathrm{sec} / \mathrm{ml}=1,333 \mathrm{~g} \mathrm{~cm}^{-4} \mathrm{sec}^{-1}$. 
made $P(t), V(t)$, and $I(t)$ appear normal in contour, as shown in Fig. 3. My criteria of normal $P(t), V(t)$, and $I(t)$ were that $P(t)$ had a plateau during ejection, $V(t)$ decreased exponentially during ejection, and $I(t)$ rapidly increased to peak at an early ejection and gradually decreased to zero. As $R$ and $\mathrm{L}$ went away from the star, $\mathrm{P}(\mathrm{t}), \mathrm{V}(\mathrm{t})$, and $\mathrm{I}(\mathrm{t})$ appeared gradually abnormal, as shown in Fig. 4. At and around the star, end ejection lagged behind end systole by $20-35 \mathrm{msec}$, or $8-14 \%$ of the duration of systole.

Now that a normal set of $\mathrm{R}$ and $\mathrm{L}$ were determined, they were fixed hereafter at the normal values and the effects of the other parameters on end ejection were studied. Fig. 5 shows isochronal zones of end ejection when arterial compliance $\mathrm{C}$ and total peripheral resistance TPR were changed. The star was plotted at $\mathrm{C}=0.33(\mathrm{ml} / \mathrm{mmHg})$ and $\mathrm{TPR}=3(\mathrm{mmHg} \mathrm{sec} / \mathrm{ml})$, which were the same normal values as used in Fig. 2. At and widely around the star, end ejection lagged behind systole by $10-100 \mathrm{msec}$, or $4-40 \%$ of the duration of systole.

Fig. 6 shows isochronal zones of end ejection when end-diastolic volume Ved and ventricular contractility index Emax were varied widely. The star was plotted at a typical set of Ved and Emax. In this plane, too, end ejec-

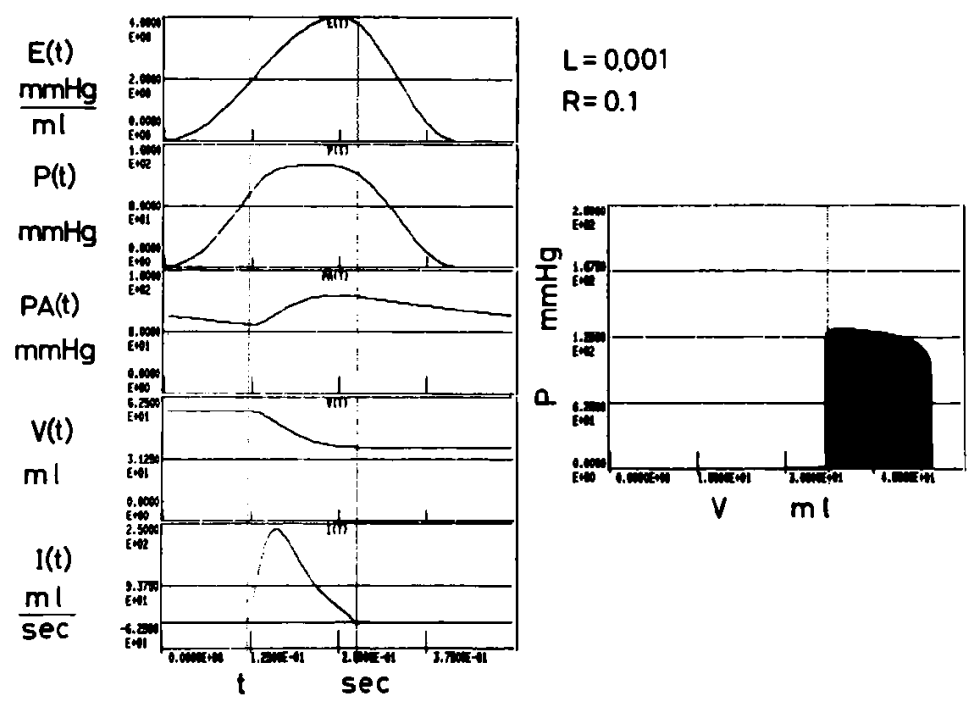

Fig. 3. Time courses of ventricular elastance $E(t)$, pressure $P(t)$, aortic pressure $\mathrm{Pa}(\mathrm{t})$, ventricular volume $\mathrm{V}(\mathrm{t})$, and aortic flow $\mathrm{I}(\mathrm{t})$ from top to bottom on the left. Ventricular pressure-volume diagram is shown on the right. All the curves appear normal. $L=0.001 \mathrm{mmHg} \mathrm{sec}^{2} / \mathrm{ml}$ and $\mathrm{R}=0.1 \mathrm{mmHg}$ $\mathrm{sec} / \mathrm{ml}$. The full scales of $\mathrm{E}(\mathrm{t}), \mathrm{P}(\mathrm{t}), \mathrm{Pa}(\mathrm{t}), \mathrm{V}(\mathrm{t})$, and $\mathrm{I}(\mathrm{t})$ on the left are 4 $\mathrm{mmHg} / \mathrm{ml}, 160 \mathrm{mmHg}, 160 \mathrm{mmHg}, 62.5 \mathrm{ml}$, and $250 \mathrm{ml} / \mathrm{sec}$ above 0 . The full scale of the time axis is $500 \mathrm{msec}$. The full scales of the pressure-volume diagram are $250 \mathrm{mmHg}$ and $60 \mathrm{ml}$. $\mathrm{Vd}=5 \mathrm{ml}$. 

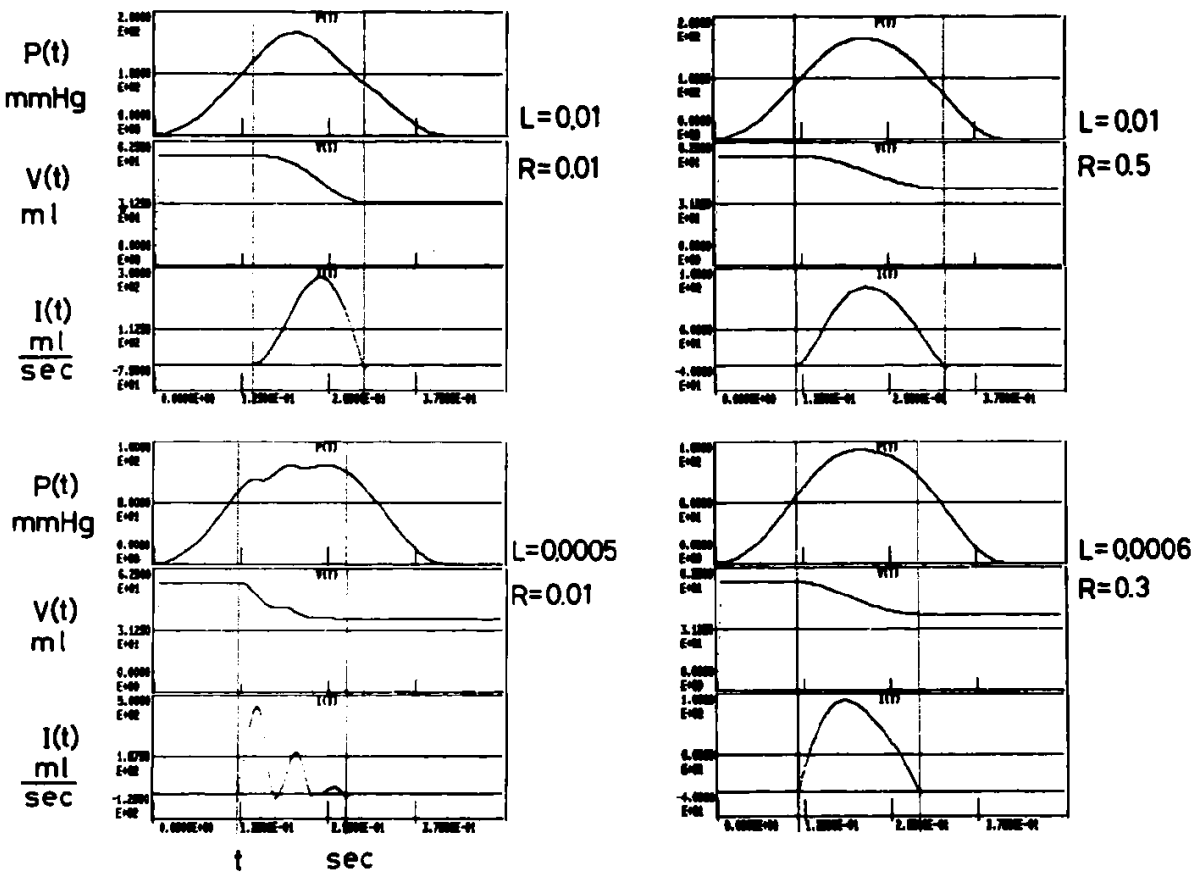

Fig. 4. Ventricular pressure $P(t)$, volume $V(t)$, and flow $I(t)$ that appear abnormal, obtained for unphysiological combinations of $L$ and $R$ as specified. The scales are the same as in Fig. 3. The dimensions of $L$ and $R$ are the same throughout the paper.

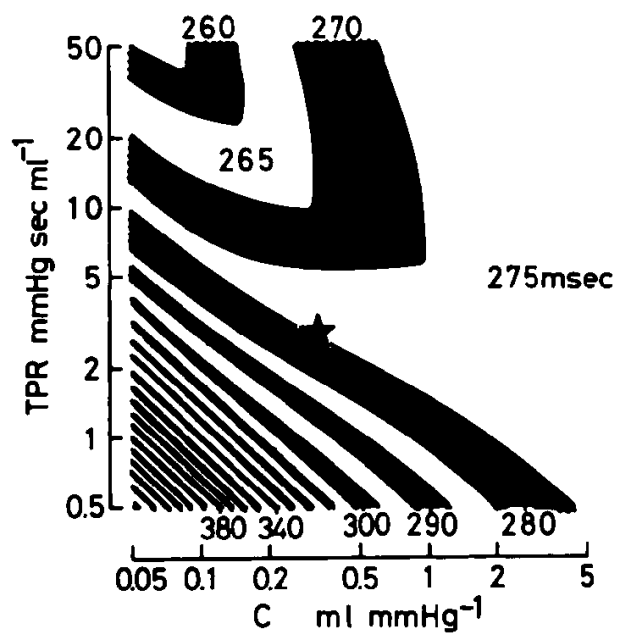

Fig. 5. Isochronal zones of end ejection with both aortic compliance $\mathbf{C}$ and total peripheral resistance TPR changed while the other parameters are fixed at those values listed in Fig. 2. $\mathrm{R}$ and $\mathrm{L}$ are the same as shown in Fig. 3. The star indicates the combination of $C$ and TPR that are listed in Fig. 2. 


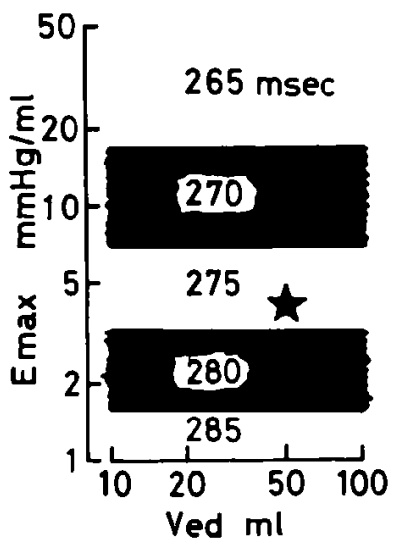

Fig. 6

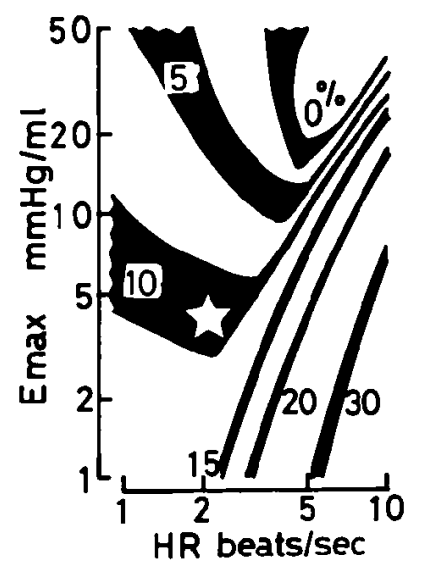

Fig. 7

Fig. 6 (left). Isochronal zones of end ejection with both end-diastolic volume Ved and contractility index Emax changed while the other parameters are fixed at those values specified in Fig. 2. $\quad R$ and $L$ are the same as specified in Fig. 3. The star indicates the combination of Ved and Emax specified in Fig. 2.

Fig. 7 (right). Isochronal zones of end ejection with both heart rate HR and Emax changed while the other parameters are fixed at those values as specified in Fig. 2. $R$ and $L$ are the same as specified in Fig. 3. The star indicates the combination of $\mathrm{HR}$ and Emax shown in Fig. 2. The time lag of end ejection from end systole is shown by percentage relative to the duration of systole because end systole is a function of heart rate.

tion lagged behind end systole for widely varied sets of Ved and Emax around the star. Changes in Ved alone did not affect end ejection.

Fig. 7 shows isochronal zones of end ejection when heart rate HR and contractility index Emax were changed widely. The star was plotted at a typical set of HR and Emax. At and widely around the star, end ejection lagged behind end systole by $5-20 \%$ of systole. End ejection coincided with and even advanced from end systole when both HR and Emax were very high.

From these representative results and other results not shown here, it was apparent that end ejection usually lagged behind end systole to a variable extent depending on the cardiovascular conditions. The two ends of systole and ejection coincided only when the system parameters took specific combinations that were considered to occur under very limited circumstances.

\section{Discussion}

The results of the present simulation have shown that end ejection is not intrinsically coincident nor identical with end systole of the ventricle. They 
can be coincident only under limited conditions of the ventricle and the afterload system. Under most conditions, end ejection variably lags behind end systole. Previously, the same ventricle model was connected to a constant pressure load and the relation between end ejection and end systole was analyzed. ${ }^{13)}$ The results were essentially the same in spite of the different load systems. Although the present as well as the previous simulation is an approximation of the actual system in vivo, similar discrepancies between end ejection and end systole are reasonably expected in vivo because the present simulation incorporates the essential features of the time-varying elastic nature of the ventricle and the Windkessel properties of the arterial system. The actual ventricle shows some viscous properties during ejection and some deactivation after ejection, ${ }^{17)}$ but these complicating properties were not included in $\mathrm{E}(\mathrm{t})$ for the sake of simplicity. Inclusion of these additional factors will affect the results quantitatively, but not likely qualitatively. A separate simulation will be needed for the quantitative results. However, well controlled animal experiments will be needed for a final conclusion.

The mechanisms underlying the relative shift of end ejection from end systole are speculated as follows. The fact that end ejection dissociates from end systole under most circumstances in the present as well as previous ${ }^{131}$ simulations indicates that the dissociation is not simply due to the pulsation of arterial pressure, arterial compliance, nor peripheral resistance. Minimizing resistance and inertance between the ventricle and artery does not help minimizing the dissociation of end ejection from end systole. The aortic valve is normally a stopper of a reversed flow, but not a valve to close merely by a pressure difference across it. ${ }^{18), 19)}$ All these factors in mind, I would speculate that the coincidence or closeness of the ends of ejection and systole which may be observed in vivo is merely a circumstantial event and not an intrinsic outcome of the ventricle. Various hemodynamic parameters of the arterial loading system affect the hemodynamic impedance of the system loaded on the ventricle and their changes will alter the timing of the onset of reversed flow relative to end systole of the ventricle. For limited combinations of those parameters, ejection will be ceased right at end systole. When the hemodynamic impedance of the artery remains unchanged, both ends of ejection and systole will be shifted with changes in ventricular contractility and heart rate and one end will shift from the other. Again, well controlled animal experiments seem needed for a final conclusion.

Consequently, it is strongly suggested that end systole in vivo cannot easily be identified by end ejection determined as the dicrotic notch of the arterial pressure curve and the minimal ventricular volume. The end ejection in vivo may be variably separated from the end systole of the ventricle 
determined as the left upper corner of the pressure-volume loop in the pressure-volume diagram.

\section{ACKNOWLEDGMENT}

The author is grateful to Dr. Ishio Ninomiya, Chairman of the Department, for his continuing encouragement in the course of this study.

\section{REFERENCES}

1. Holt JP: Regulation of the degree of emptying of the left ventricle by the force of ventricular contraction. Circulat Res 5: 281, 1957

2. Katz LN: The Lewis A Corner memorial lecture. The performance of the heart. Circulation $21: 483,1960$

3. Suga $H$, Sagawa $K$, Shoukas AA: Load independence of the instantaneous pressure-volume ratio of the canine left ventricle and effects of epinephrine and heart rate on the ratio. Circulat Res 32: 314, 1973

4. Suga $\mathbf{H}$, Sagawa $\mathrm{K}$ : Instantaneous pressure-volume relationships and their ratio in the excised, supported canine left ventricle. Circulat Res 35: 117, 1974

5. Weber KT, Janicki JS, Hefner LL: Left ventricular force-length relations of isovolumic and ejecting contractions. Am J Physiol 231: 337, 1976

6. Grossman W, Braunwald E, Mann T, McLaurin LP, Green LH: Contractile state of the left ventricle in man as evaluated from end-systolic pressure-volume relations. Circulation 56: 845,1977

7. Sagawa K: The ventricular pressure-volume diagram revisited. Circulat Res 43: 677, 1978

8. Sasayama S, Kotoura H: Echocardiographic approach for clinical assessment of left ventricular function. The analysis of end-systolic pressure (wall stress)-diameter relation and force-velocity relation of ejecting ventricle. Jpn Circulat J 43:357, 1979

9. Wiggers CJ: Circulatory Dynamics-Physiologic Studies. Grune \& Stratton, New York, 1952

10. Suga H, Kitabatake A, Sagawa K: End-systolic pressure determines stroke volume from end-diastolic volume in isolated canine left ventricle under constant contractile state. Circulat Res 44: 238, 1979

11. Ishide N, Shimizu Y, Maruyama Y, Koiwa Y, Nunokawa T, Isoyama S, Kitaoka S, Tamaki $\mathrm{K}$, Inooka $\mathrm{E}$, Takishima $\mathrm{T}$ : Effects of changes in the aortic input impedance on systolic pressure-ejected volume relationships in the isolated supported canine left ventricle. Cardiovasc Res 14: 229, 1980

12. Maughan WL, Shoukas AA, Sagawa $\mathrm{K}$, Weisfeldt ML: Instantaneous pressure-volume relationship of the canine right ventricle. Circulat Res 44: 309, 1979

13. Suga $\mathrm{H}$, Nishiura $\mathrm{N}$ : Dissociation of end ejection from end systole of ventricle. Jpn Heart J 22: 1, 1981

14. DeFares JG, Hara HH, Osborne JJ, McLeon J: Theoretical analysis and computer simulation of the circulation with special reference to the Starling properties of the ventricle. in Circulatory Analog Computer, North-Holland, Amsterdam, p91, 1963

15. Beneken JEW, DeWit B: A physical approach to hemodynamic aspects of the human cardiovascular system. in Physical Bases of Circulatory Transport: Regulation and Exchange, Saunders, Philadelphia, p1, 1967

16. Westerhof N, Elzinga G, Sipkema P: An artificial arterial system for pumping hearts. J Appl Physiol 31 : 776, 1971

17. Suga H, Sagawa K, Demer L: Determinants of instantaneous pressure in canine left ven- 
tricle. Time and volume specification. Circulat Res 46: 256, 1980

18. Spencer MP, Greiss FC: Dynamics of ventricular function. Circulat Res 10: 274, 1962

19. Noble MIN: The contribution of blood momentum to left ventricular ejection in the dog. Circulat Res 23: 663, 1968 